\title{
Chapter 15 \\ Reduction of Air Radiation Dose by Ponding Paddy Fields
}

\author{
Naritaka Kubo, Toshiaki Iida, and Masaru Mizoguchi
}

\begin{abstract}
Radioactive cesium (Cs) released by nuclear accidents is sorbed and fixed onto soil surfaces, which then radiate strong gamma rays ( $\gamma$-rays). Decontamination around dwelling areas is now eagerly being implemented but more efforts are necessary to reduce the air radiation dose. Paddy field ponding, from the viewpoint of cost-effectiveness, is considered to be an effective practice for reducing the air radiation dose in the environment. In this study, field experiments were conducted at Sasu and Komiya regions in Iitate Village to verify the effectiveness of paddy field ponding, and numerical experiments were also conducted using the formula for uncollided $\gamma$-ray fluxes passing through the shield material.

It was found that the a ponding water depth of $20-25 \mathrm{~cm}$ can drastically reduce the number of $\gamma$-ray photons emitted from the paddy fields, and the reduction in radiation dose was related to water depth. However, some differences were also observed between field and numerical experiments. The numerical calculation showed that the radiation dose decreased exponentially when the depth increased; however, field experiments showed a linear decrease. The cause might be the buildup effect caused by Compton scattering, but the details are unclear. It is necessary to explain these differences before ponding becomes a useful practice.
\end{abstract}

Keywords Decontamination - Gamma ray • Paddy field ponding • Puddling • Radiation shielding $\bullet$ Half-value thickness

\author{
Abbreviation \\ Cs Cesium \\ $\gamma$-ray Gamma ray \\ $\mathrm{Bq} \quad$ Becquerel \\ Sv Sievert
}

N. Kubo $(\bowtie) \cdot$ T. Iida $\bullet$ M. Mizoguchi

Graduate School of Agricultural and Life Sciences, The University of Tokyo, 1-1-1, Yayoi,

Bunkyo-ku, Tokyo 113-8657, Japan

e-mail: anakubo@mail.ecc.u-tokyo.ac.jp 


\subsection{Introduction}

Three and a half years have passed since the Great East Japan earthquake (March 11, 2011), and earnest decontamination works are now being implemented around the dwelling areas of IITATE village. Radioactive substances are surely reduced by the decontamination works and are also gradually diminishing through runoff and decay. In the near future, the evacuation order will be lifted at "zones in preparation for the lifting of the evacuation order" successively when the air radioactive dose becomes sufficiently low (Minyu-net 2014). However, more efforts are necessary to reduce the radioactivity before the evacuated villagers return. Among some of the measures is "paddy field paddling and ponding," which is considered to be feasible in terms of cost-effectiveness and farmland conservation.

Gamma rays ( $\gamma$-rays), which are generated when radioactive Cesium (Cs) decays, are a form of electromagnetic radiation like visible light; they behave just like particles and are emitted in every direction (Tazaki 2011). In the case of paddy fields, Cs fixes onto the soil surface (Shiozawa et al. 2011), and because the field surface is flat, the soil can be a major source of $\gamma$-rays if there is no obstructive shielding. However, if the paddy fields are ponded, the $\gamma$-rays coming from the paddy field can be reduced considerably. Thus, even if the living space is close to the paddy field, the $\gamma$-ray photons are substantially reduced because the $\gamma$-rays heading toward the living space have a low elevation angle and they must cross the ponded water layer obliquely with long path length.

Most Japanese paddy fields are irrigated unlike upland fields, and they are equipped with irrigation facilities to supply them with water. Some facilities were damaged by the earthquake, but minor repairs and maintenance can recover their functions. Only supplying water to the paddy field, however, cannot attain maintaining ponding depth; they need puddling and border coating. Without these practices, ponded water is rapidly lost by vertical and horizontal percolation (Lee et al. 2003). Puddling disperses Cs within the plow layer, and the $\gamma$-ray dose can be reduced by soil and saturated soil water. The puddling also prevents the dust, which sorbs Cs, from being blown up. Besides, paddy field ponding is effective for preventing the growth of weeds and invasion by wild animals like wild boars and monkeys. If the soil-to-rice transfer of radioactive cesium is permissible, then rice cultivation in a deeply ponded paddy field will be a big step for reconstructing the village.

In this paper, the effects of paddy field ponding will be verified through field experiments and numerical calculations, and problems will be discussed relating to field experiments and field application. 


\subsection{Theoretical Consideration}

Firstly, the dangers of non-ponded paddy fields will be proven by a simple calculation. Let's consider three radiation sources located at points $\mathrm{A}(-\varepsilon, 0), \mathrm{O}(0,0)$, and $\mathrm{B}(\varepsilon, 0)$ on the $x$-axis as shown in Fig. 15.1. Point $\mathrm{P}(x, y)$ is remote from $\mathrm{O}$ by the distance $r$, and $r$ is assumed to be much longer than the interval $\varepsilon(r \gg \varepsilon)$.

The changes of the $\gamma$-ray intensity at point P and the visual angle $\omega(\angle \mathrm{APB})$ are examined when the elevation angle, $\theta$ changes. As the $\gamma$-rays are emitted in every direction from the source, the intensity is inversely proportional to the square of the distance from the source. The square of the distance from $A$ to $P$, and the reciprocal of the square can be approximated as follows.

$$
\begin{gathered}
\overline{A P}^{2}=(x+\varepsilon)^{2}+y^{2}=r^{2}\left(1+2 \frac{x \varepsilon}{r^{2}}+\frac{\varepsilon^{2}}{r^{2}}\right) \cong r^{2}\left(1+2 \frac{x \varepsilon}{r^{2}}\right) \\
\frac{1}{\overline{A P}^{2}} \cong \frac{1}{r^{2}}\left(1-2 \frac{x \varepsilon}{r^{2}}\right)
\end{gathered}
$$

Therefore, as shown below, the total intensity of the $\gamma$-rays from three sources is about three times that from only one source at $\mathrm{O}$ regardless of the elevation angle, $\theta$.

$$
\frac{1}{\overline{A P}^{2}}+\frac{1}{\overline{O P}^{2}}+\frac{1}{\overline{B P}^{2}} \cong \frac{1}{r^{2}}\left(1-2 \frac{x \varepsilon}{r^{2}}\right)+\frac{1}{r^{2}}+\frac{1}{r^{2}}\left(1+2 \frac{x \varepsilon}{r^{2}}\right)=\frac{3}{r^{2}}
$$

This means that the radiation dose at $\mathrm{P}$ is proportional to the number of sources and does not depend on the elevation angle, $\theta$.

On the other hand, when $r \gg \varepsilon$, three lines AP, OP, and BP become almost parallel and the following relationship can be obtained for the visual angle $\omega$, as shown in Fig. 15.2.

Fig. 15.1 Three radiation point sources at $\mathrm{A}, \mathrm{O}$, and $\mathrm{B}$ on the plane and a receiver at $\mathrm{P}$

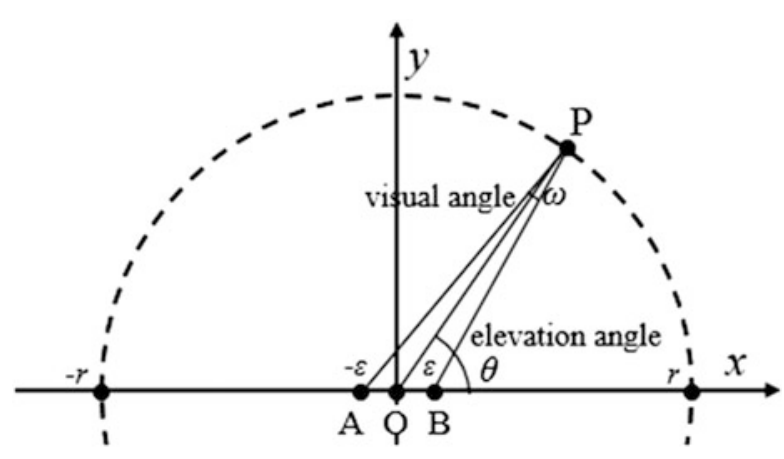


Fig. 15.2 Visual angle $\omega$ vs. elevation angle $\theta$ when distance $r$ is much longer than interval $\varepsilon$

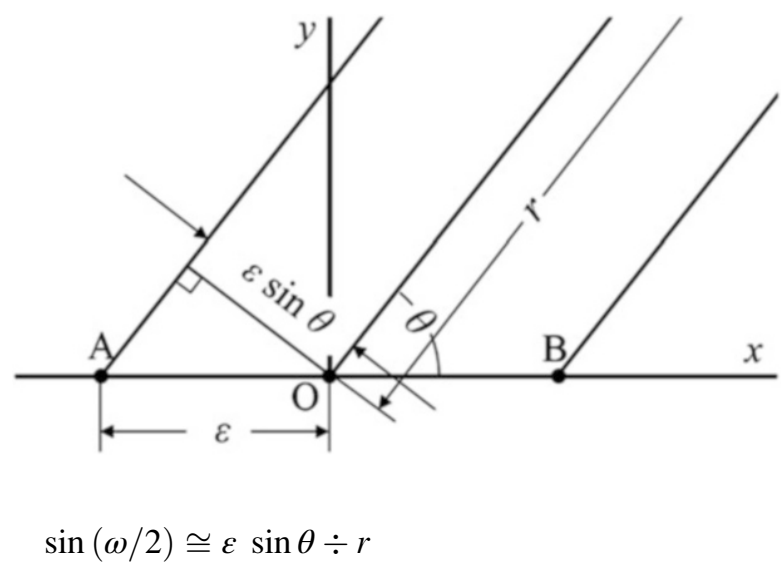

Furthermore, as $\sin (\omega / 2) \cong \omega / 2$ when $\omega$ is small, the visual angle $\omega$ is approximated by the following equation.

$$
\omega \cong 2(\varepsilon / r) \sin \theta
$$

The visual angle takes a maximum value of $2(\varepsilon / r)$ when $\theta=\pi / 2$, and is zero when $\theta=0$. As the total intensity of the $\gamma$-ray is constant regardless of $\theta$, the intensity per unit visual angle becomes very strong (bright) when the visual angle $\omega$, relative to the elevation angle $\theta$, becomes small. The above considerations are realized when the paddy field is undisturbed, because the Cs settles from the air onto the soil surface, and the paddy field surface is artificially flat. Consequently, the undisturbed paddy fields are very dangerous for people staying in the course of the $\gamma$-rays emitted with a small elevation angle.

Secondly, the shield effectiveness of soil or water against the $\gamma$-rays will be examined. Gamma radiation is an electromagnetic wave, but it behaves as a photon and is mainly attenuated by electron to $\gamma$-ray interactions when it passes through a substance. The number of photons is attenuated $\mathrm{e}^{-\mu d}$ times when they pass through a substance having a thickness of $d$. This $\mu$ is called the linear attenuation coefficient, and $\mu_{\mathrm{m}}(=\mu / \rho$, where $\rho$ is density) is called the mass attenuation coefficient (Tazaki 2011). The value of $\mu_{\mathrm{m}}$ is almost constant regardless of the kind of substance, and therefore the value of $\mu$ is nearly proportional to the density of the substance. The thickness of $d_{0.5}$, through which the number of photons is halved, is called the halfvalue thickness. The values of $d_{0.5}$ for water, air, and soil are $8.1 \mathrm{~cm}, 70 \mathrm{~m}$, and about $5 \mathrm{~cm}$, respectively, for $\gamma$-rays emitted from ${ }^{137} \mathrm{Cs}$ (Fujiwara 2011).

Figure 15.3 shows that the pass length is $d / \sin \theta$ when the thickness is $d$ and the elevation angle is $\theta$. The reduction ratio of photons is calculated by the following equation. 


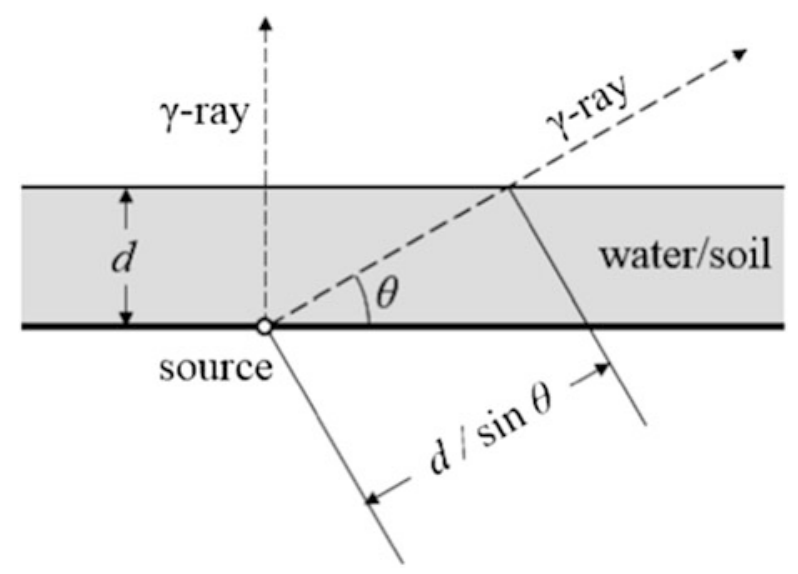

Fig. 15.3 Travel length of the $\gamma$-ray in the medium of water or soil

(a) Normal aspect ratio

(b) Different aspect ratio where height is emphasized

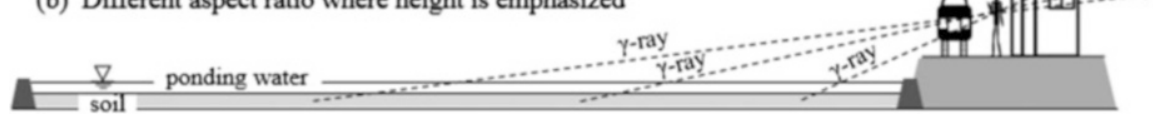

Fig. 15.4 Gamma rays radiated from the paddy field to the living space

$$
0.5^{\frac{d}{d_{0.5}} \times \frac{1}{\sin \theta}}=\left(0.5^{\frac{d}{d_{0.5}}}\right)^{\frac{1}{\sin \theta}}
$$

Contrary to this case, the shield effectiveness of water/soil is enormous when the elevation angle is small, and such shield effect is superior to the amplification effect due to the low elevation angle. Specifically, if the thickness $d$ is equal to the halfvalue thickness $d_{0.5}$, then the reduction ratios of photons are $1 / 4,1 / 15,1 / 55$, and $1 / 3000$, and the brightness ratios are $1 / 2,1 / 4,1 / 10$, and $1 / 250$ when the elevation angles are $30^{\circ}, 15^{\circ}, 10^{\circ}$, and $5^{\circ}$, respectively.

The above consideration shows that paddy fields are no longer dangerous if the radioactive substances are mixed with soil by plowing, the mixed soil is then saturated with water by puddling, and the paddy fields are kept deeply ponded. All of these measures can considerably reduce the number of photons that would otherwise be emitted to the air. They can be especially effective for enabling daily living spaces, which are in the course of the $\gamma$-rays with a low elevation angle. Figure 15.4 shows the $\gamma$-ray radiation from paddy fields to living spaces: (a) the aspect ratio is normal and (b) the aspect ratio is different to emphasize the height. 
It can be seen from Fig. 15.4 that the actual elevation angle of the $\gamma$-ray course is very low, and the pass length in soil/water becomes very long, which will contribute to attenuation of the $\gamma$-ray intensity.

\subsection{Field Experiments}

Two sections in IITATE village, Sasu and Komiya, were selected for the field experiments to examine the effects of ponding paddy fields on the reduction of air radiation. The experiment at Sasu was preliminary and the observation period was less than 1 month from the 13th of October 2012 to the 10th of November 2012. The main experiment was at Komiya, where the observation period was 4 months from the 3rd of August 2013 to 3rd of December 2013.

\subsubsection{Field Experiment at Sasu}

This section was designated as "zone in preparation for the lifting of the evacuation order," and the radiation dose was relatively low. The experimental paddy field was situated at lat. $37^{\circ} 44^{\prime} 15^{\prime \prime}$ and long. $140^{\circ} 43^{\prime} 44^{\prime \prime}$, and was located at the bottom of a hill surrounded by forests extending to the west and east.

Figure 15.5 shows the configuration of the paddy fields and locations of observation equipment for the $\gamma$-ray intensity ( $\gamma$-ray) and ponding depth (WL). The point $\mathrm{A}$ is located at the corner of the paddy field, and the point $\mathrm{B}$ is at the center of the paddy field but is $1 \mathrm{~m}$ outside the border. Water was taken from an irrigation ditch and was drained to the natural stream nearby. Only one paddy field was supplied with water, but the others were not. However, some partial ponding was observed in the right-side neighboring paddy field, which received some percolating water that seeped out from the ridge. A Geiger Müller counter installed $1 \mathrm{~m}$ above the paddy field surface measured the $\gamma$-ray intensity. This type of counter, however, cannot distinguish decaying radioactive elements, and therefore it was difficult to accurately measure radioactive doses.

The amount of ${ }^{134} \mathrm{Cs}$ and ${ }^{137} \mathrm{Cs}$ decreases by natural decay over time. About $2.8 \%$ of ${ }^{134} \mathrm{Cs}$ and $0.2 \%$ of ${ }^{137} \mathrm{Cs}$ decreased in 1 month, but these decreases were not compensated for in the experiment at Sasu. Figure 15.6a shows the time series of the $\gamma$-ray counting per hour at points A and B. The counts represent the daily mean because it fluctuated intensely. Figure 15.6b shows the time series of ponding water levels, the reference of which is the mean altitude of the paddy field surface. The elevation of point $\mathrm{C}$ was about $6 \mathrm{~cm}$ lower than the mean value because the field surface was slightly inclined to the north side, and water depth $\mathrm{h}=0 \mathrm{~cm}$ corresponds to $\mathrm{WL}=-6 \mathrm{~cm}$.

Figure 15.7a shows the relationship between the ponding water level and the $\gamma$-ray counts at points $\mathrm{A}$ and $\mathrm{B}$. The radiation counts were observed to decrease by 


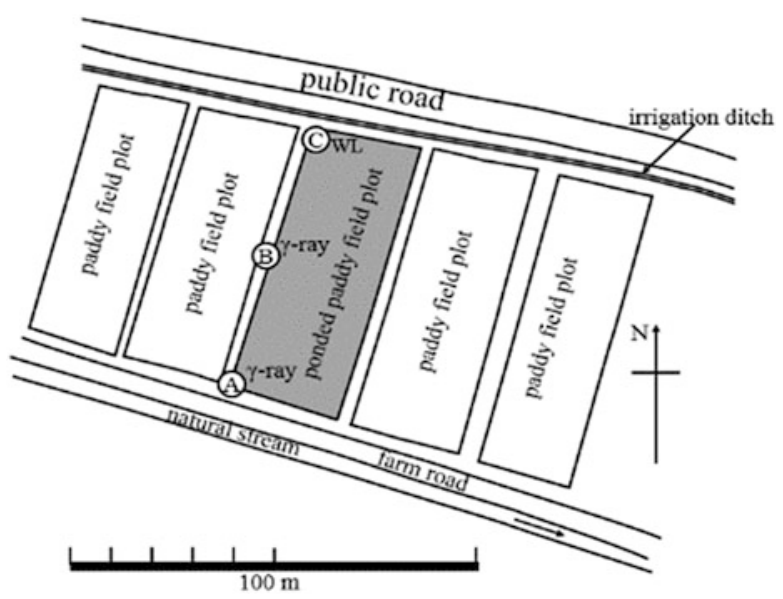

Fig. 15.5 Experimental paddy field in Sasu. Section and locations of observation stations for $\gamma$-rays and water levels
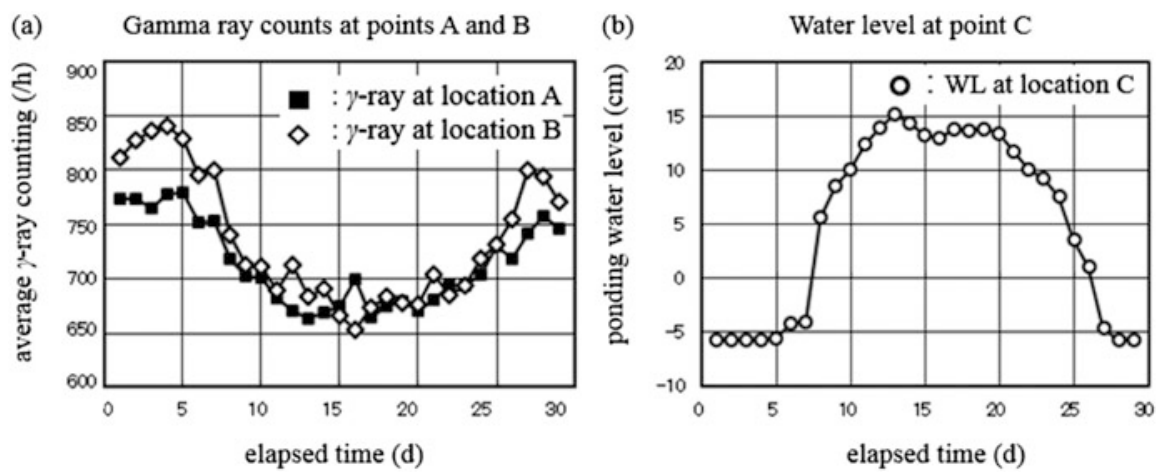

Fig. 15.6 Field observations of $\gamma$-ray radiation and water level

4.57 counts at point $\mathrm{A}$ and by 6.79 counts at point $\mathrm{B}$, which corresponded to a rise in water level of $1 \mathrm{~cm}$. Figure $15.7 \mathrm{~b}$ shows the correlation of concurrent radiation counts at points $\mathrm{A}$ and $\mathrm{B}$, and shows that the decreasing rate at $\mathrm{B}$ was 1.43 times larger than that at A.

Theoretically, the uncollided $\gamma$-ray flux can be calculated against the ponding depth; however, it does not directly correspond to the effective dose because it does not consider scattering. The flux $I$, the number of $\gamma$-ray photons, which pass per unit time through an orbicular head having a unit cross section, can be calculated using the following equation. 

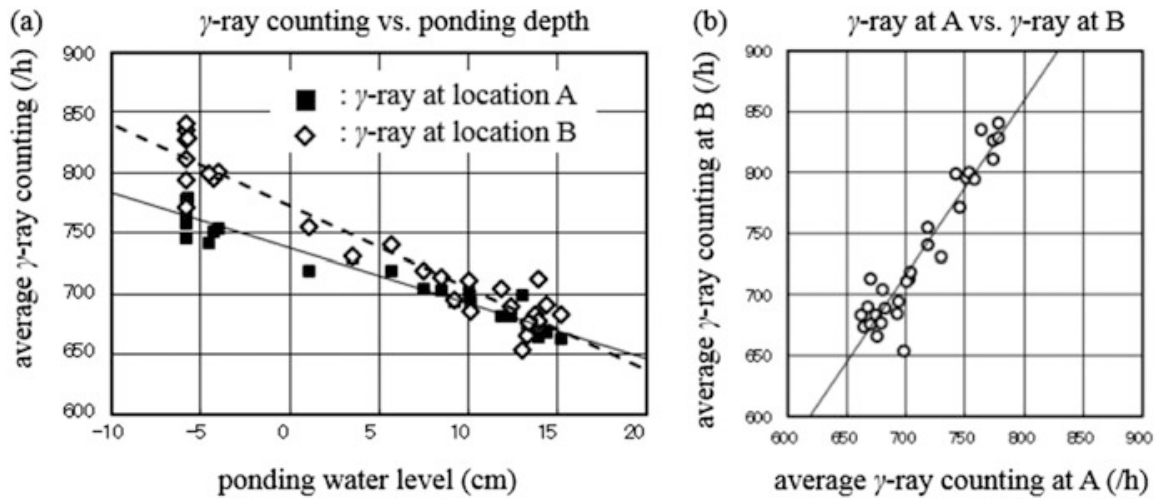

Fig. 15.7 Relationship between $\gamma$ - ray counts and ponding depth at points A and B

$$
I=\frac{p}{4 \pi} \iint_{S} \frac{(0.5)^{\sqrt{r^{2}+h^{2}} \times\left(\frac{h-d}{h d_{0.5 a}}+\frac{d}{h d_{0.5 w}}\right)}}{r^{2}+h^{2}} d s=\frac{p}{4 \pi} \alpha
$$

where, $p$ is the number of $\gamma$-ray photons emitted from unit paddy field area in unit time, $S$ is the area of the target paddy field, $r$ is the horizontal distance from the observation point to an element having small area $d s, h$ is the height of the $\gamma$-ray counter, $d$ is the ponding depth, $d_{0.5 \mathrm{a}}$ is the half-value thickness of air, and $d_{0.5 \mathrm{w}}$ is the half-value thickness of water.

The integral $\alpha$ in the above equation depends on ponding depth $d$, height $h$, and paddy field shape, but the latter two do not change; therefore $\alpha$ is a function of $d$. In the case where the radiation intensity, $p$, depends on location and the elapsed time $t$ after the nuclear accident, and if the value for $p$ is assumed to be same in each paddy field, then $p$ is only a function of $t$. The integrals $\alpha_{\mathrm{A}}$ and $\alpha_{\mathrm{B}}$ are calculated numerically; the target paddy field of $80 \mathrm{~m} \times 25 \mathrm{~m}$ is divided into squares of $0.5 \mathrm{~m} \times 0.5 \mathrm{~m}$, and evenly distributed radioactive substances are assumed to exist at the center of each square, as shown in Fig. 15.8.

Figure 15.9 shows the numerical results of integrals $\alpha_{\mathrm{A}}$ and $\alpha_{\mathrm{B}}$. It is difficult to directly compare the measured and calculated results in Figs. 15.7 and 15.9; however, several differences and similarities were observed with regard to the shielding effect of ponding. Firstly, for the reduction pattern of the $\gamma$-rays against the ponding depth, the $\gamma$-ray counts decreased linearly in Fig. 15.7, but the integral $\alpha$ decreased exponentially in Fig. 15.9.

The effect may be attributed to Compton scattering. The $\gamma$-ray counts were measured by using a Geiger Müller counter, which counts $\gamma$-rays scattered by the Compton effect as well as uncollided $\gamma$-rays. In such cases, the $\gamma$-ray flux is built up and "the exponential relation" in Fig. 15.9 may approach to "the linear relation" in Fig. 15.7. Secondly, regarding the reduction rates at points A and B, those at point $A$ were 1.4-1.5 times larger than those at point $\mathrm{B}$. This relationship is seen commonly 


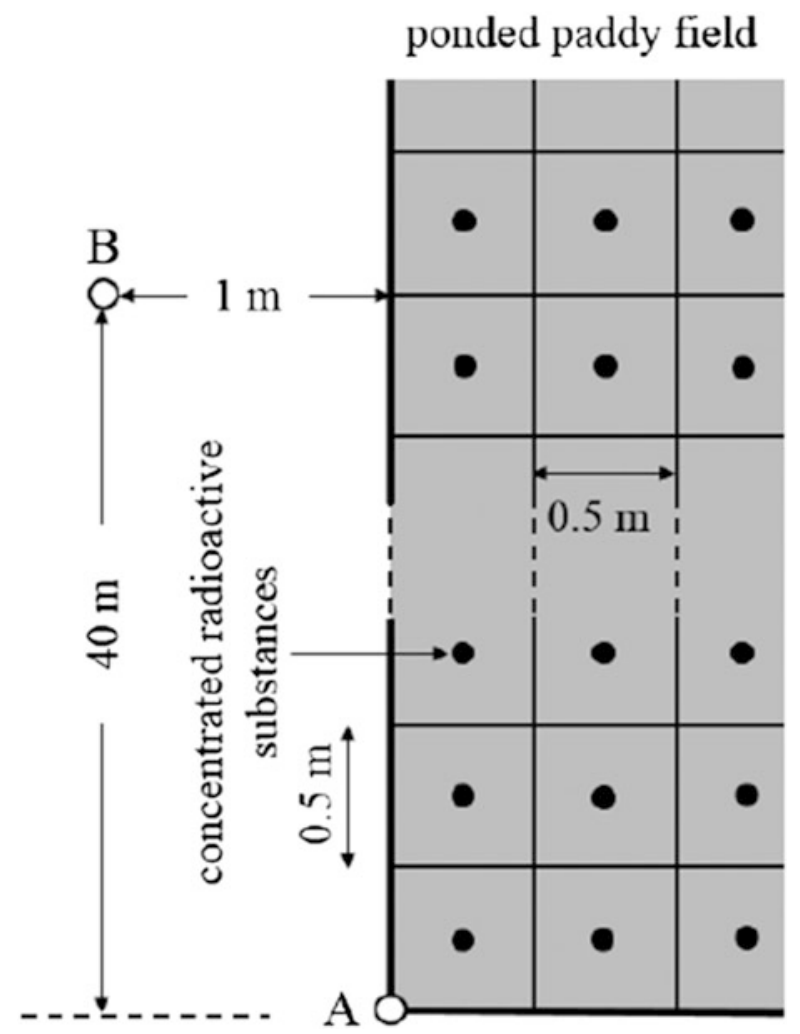

Fig. 15.8 Paddy field and observation points A and B for numerical calculation of uncollided $\gamma$ ray flux. Paddy field is divided into squares of $0.5 \mathrm{~m} \times 0.5 \mathrm{~m}$ and distributing radioactive substances are assumed to be concentrated at the center of each square

(a) integrals $\alpha_{A}$ and $\alpha_{B}$ vs. ponding depth

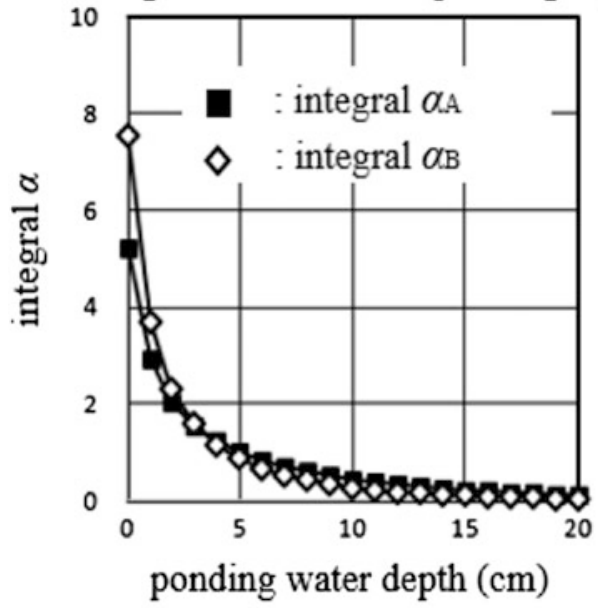

(b) integral $\alpha_{\mathrm{A}}$ vs. integral $\alpha_{\mathrm{B}}$

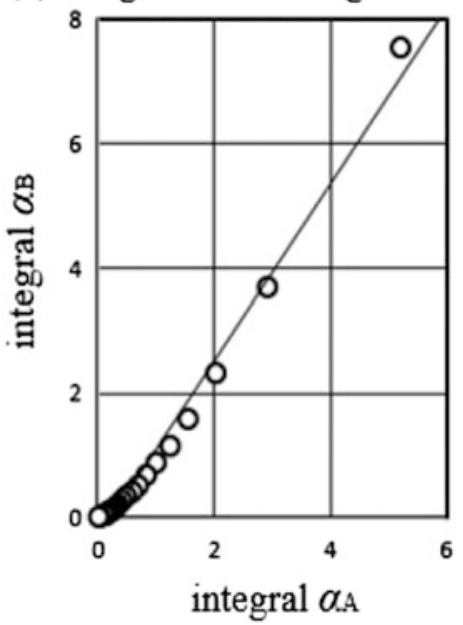

Fig. 15.9 Relationship between integral $\alpha$ and ponding depth at A and B 
in the measured and calculated results presented in Figs. 15.7 and 15.9. Theoretically, the reduction rate at $\mathrm{B}$ was 2.0 times that at $\mathrm{A}$, if the sensor was set on the border of the paddy field, but actually it was set $1 \mathrm{~m}$ outside the border. In any case, if the ponding depth is kept at about $20 \mathrm{~cm}$, then the uncollided $\gamma$-ray flux is reduced to $2 \%$ of the original flux intensity, and the $\gamma$-ray reduction effects by the water ponding are confirmed to be significant.

\subsubsection{Field Experiment at Komiya}

This section is designated as a "restricted residential area," and the experimental paddy fields are situated at lat. $37^{\circ} 37^{\prime} 31^{\prime \prime}$ and long. $140^{\circ} 46^{\prime} 37^{\prime \prime}$ and are surrounded by forests. Figure 15.10 shows the configuration of the paddy fields and the locations of observation equipment for the $\gamma$-ray intensity ( $\gamma$-ray) and ponding depth (WL). Two paddy field plots were used for the experiment. Ponding depths were measured at point $\mathrm{F}$ for the left side plot and at point $\mathrm{G}$ for the right side plot using U20 water level loggers (Onset Computer Corporation).

The radiation doses were measured at points D and E using GPSGMC-002-TUV loggers (SERIALGAMES Inc.). Point D is on a road, and on both sides of the road are paddy fields. The detailed location is 0.5 and $2.5 \mathrm{~m}$ from the left side and right side borders, respectively. Point $\mathrm{E}$ is in front of the house and is located $0.5 \mathrm{~m}$ outside the paddy field border. Other paddy fields and upland fields are nearby two experimental fields, and forests surround all these fields. These fields and forests are possible sources of $\gamma$-ray background, but it is considered to change only mildly

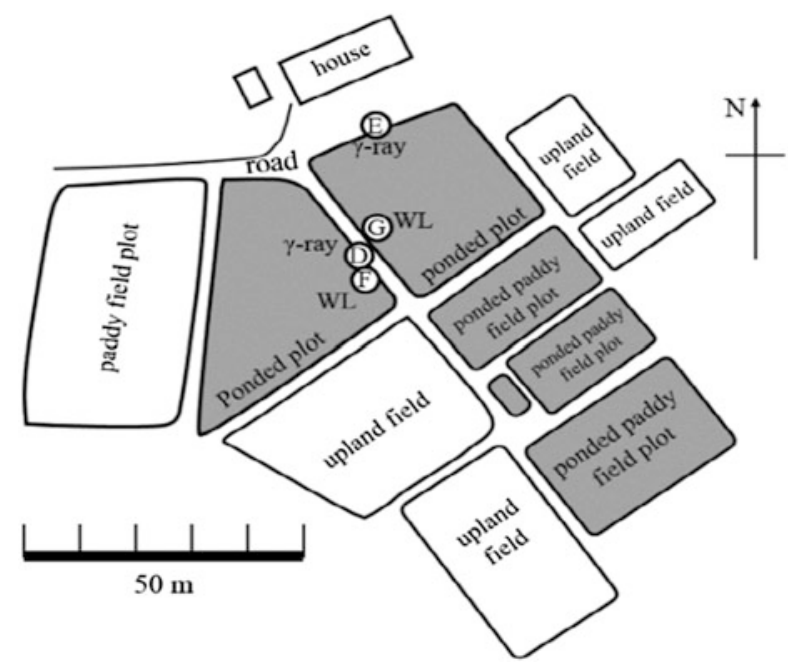

Fig. 15.10 Experimental paddy fields in Komiya section and locations of observation stations for $\gamma$-rays and water levels 


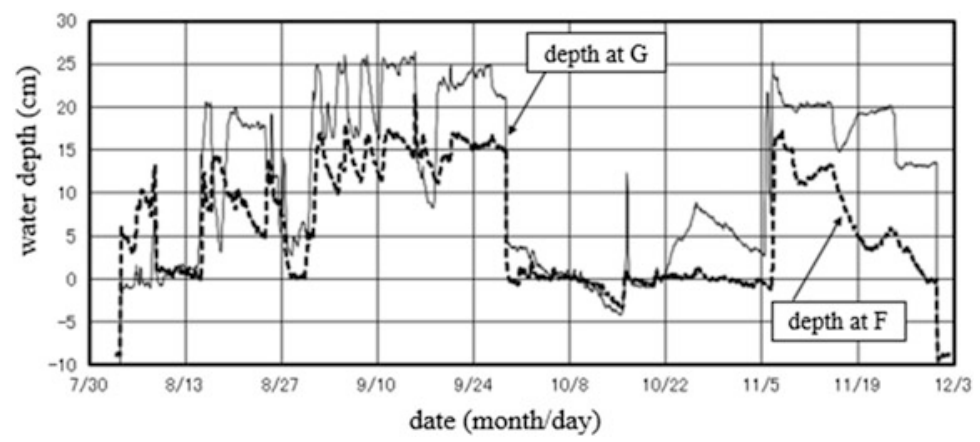

Fig. 15.11 Time series of water depth at F and $G$

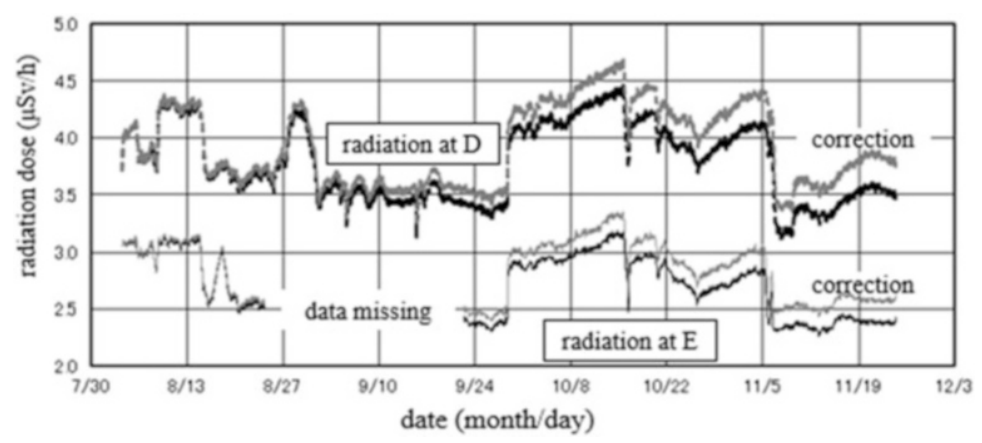

Fig. 15.12 Time series of $\gamma$-ray radiation dose at D and E. Black line: raw data. Gray line: corrected data considering decay

even if it changes seasonally. Figure 15.11 shows the time series of ponding depths at points $\mathrm{F}$ and $\mathrm{G}$. The observation period was divided into four for convenience: the August term was from the 3rd to the 31st August with relatively deep ponding depth; the September term was from the 1st to the 28th September with very deep ponding depth; the October term was from the 29th September to the 5th November with very shallow ponding depth; and the November term was from the 6th November to the 3rd December with relatively deep ponding depth.

Figure 15.12 shows the time series of radiation doses at points $\mathrm{D}$ and $\mathrm{E}$. At the point E, no data were recorded during the September term because of equipment issues. The observation period at Komiya was 4 months, which is too long to ignore the natural decay, and some kind of correction was needed to compensate for the decrease in radioactivity.

The radiation dose for each day was corrected to the equivalent dose on the 3rd of August assuming the following conditions: the Becquerel (Bq) abundance ratio of ${ }^{134} \mathrm{Cs}$ and ${ }^{137} \mathrm{Cs}$ was 1:1 at the beginning, their half-lives are 2.06 and 30.2 years; the conversion ratio from $\mathrm{Bq}$ to Sievert (Sv) is 5.5: 2.1, and the elapsed time is 870 days from the day of the accident to August 3. The black line in Fig. 15.12 shows the before correction dose and the gray line shows the after correction dose. The dose decreased by $\sim 8 \%$ during the 4 months. 

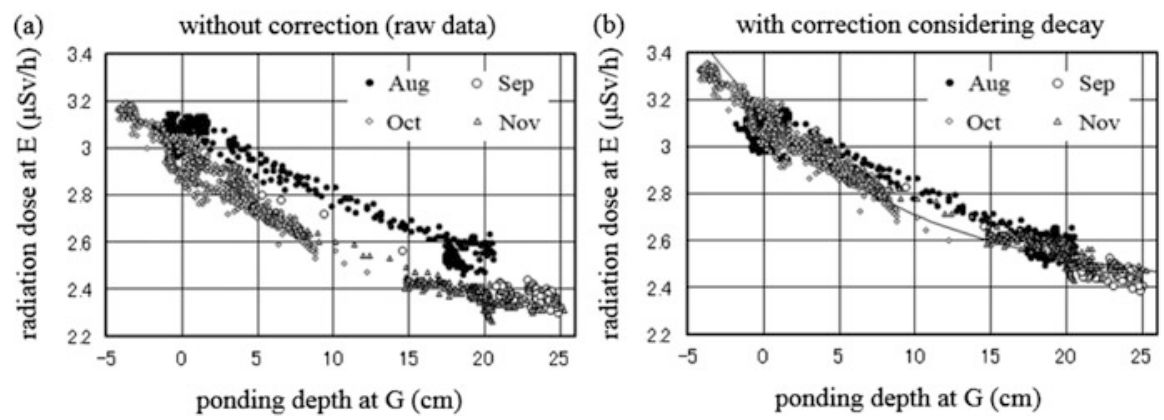

Fig. 15.13 Radiation dose at E (in front of the house) vs. ponding depth at G (right side paddy field)

Figure 15.13 presents the relationship between the radiation dose at point $\mathrm{E}$ and the ponding depth of the right side paddy field (observed at point G). A clear spreading of data can be seen between the early and late data in Fig. 15.13a which uses raw data, but such a spreading of data cannot be seen in Fig. 15.13b which uses corrected data. Considering the above results, our analyses from this point on will use corrected data (values equivalent to those on August 3rd). The radiation dose corresponding to the increase of the ponding depth decreased exponentially, although it decreased slowly. The regression curve of the radiation dose $y(\mu \mathrm{Sv} / \mathrm{h})$ may be approximated by an exponential function of depth $h(\mathrm{~m})$ as follows.

$$
\begin{aligned}
\mathrm{y} & =2.38+1.16 \times \operatorname{Exp}(-8.38 \times(h+0.05)) \\
& =3.54-1.16 \times\{1-\operatorname{Exp}(-8.38 \times(h+0.05))\}
\end{aligned}
$$

This equation shows that the radiation dose was $3.54(\mu \mathrm{Sv} / \mathrm{h})$ if the field was not ponded ( $h=-0.05 \mathrm{~m}$, because of the uneven field surface), but it decreased to 2.38 $(\mu \mathrm{Sv} / \mathrm{h})$, which corresponds to background radiation, if the $\gamma$-rays from the relevant field were perfectly obstructed.

Figure 15.14 shows the time series of the radiation dose at E; the solid line is observed and the dotted line is estimated from the depth at point $G$ using this regression curve. This regression curve can complement the lack of data, but it tends to overestimate dose values when they are large.

Although point $E$ is scarcely influenced by the far left side paddy field, point $D$ is surely influenced by paddy fields on both sides. Figure $15.15 \mathrm{a}$ shows the relationship between the radiation dose at $\mathrm{D}$ and the averaged ponding depth at $\mathrm{F}$ and G. The plotted points are distributed over a wide range, especially the scattered points marked by $\Delta$ which were observed in November when the ponding depths at either side were considerably different. Figure $15.15 \mathrm{~b}$ shows the relationship between the radiation dose at $\mathrm{D}$ and the ponding depth at point $\mathrm{F}$ in the left side paddy field; the plotted points are still distributed over a wide range. 


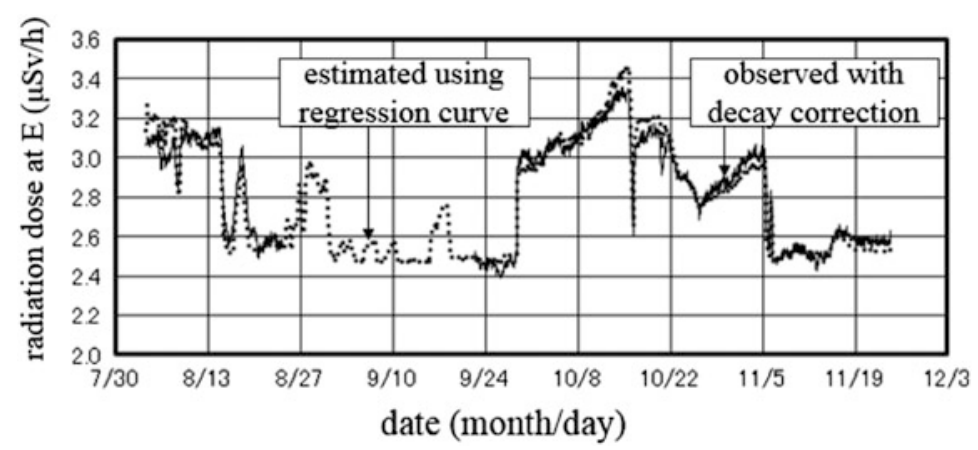

Fig. 15.14 Estimated radiation dose at $\mathrm{E}$ using a regression curve
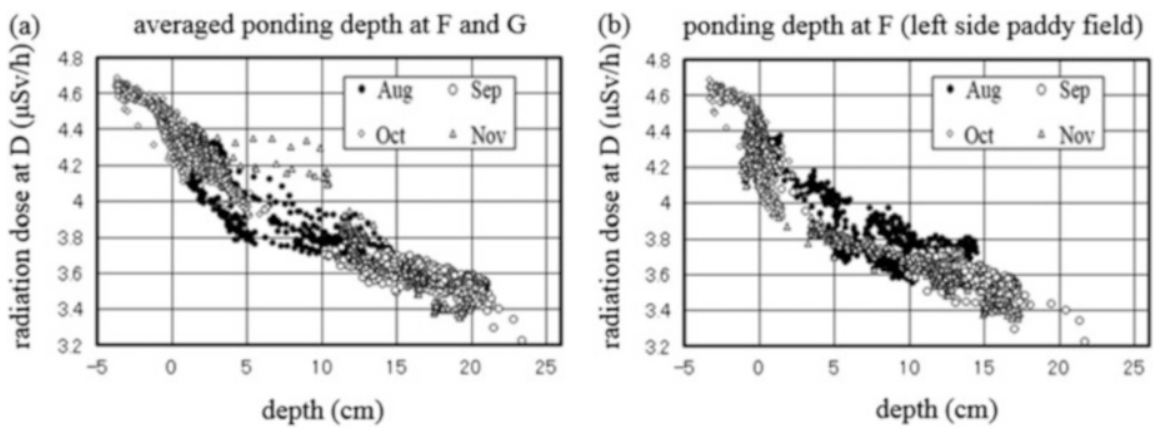

Fig. 15.15 Radiation dose at D (on the road) vs. ponding depth

To make the relationship clear between the radiation dose at $\mathrm{D}$ and the ponding depth at $\mathrm{F}$, the influence of the right side paddy field must be removed. Accordingly, a numerical calculation of uncollided $\gamma$-ray flux was utilized to estimate the influence of the right side paddy field on radiation doses at points $\mathrm{D}$ and $\mathrm{F}$. The shape of the right side paddy field is a distorted rectangle as seen in Fig. 15.10, but it is approximated to a rectangle in Fig. 15.16 with the point $\mathrm{D}$ being $2.5 \mathrm{~m}$ from the long side border and the point $\mathrm{E}$ being $0.5 \mathrm{~m}$ from the short side border. As the value of $p$ in Eq. (15.1) was assumed constant, the radiation doses at D and $\mathrm{F}$ are proportional to the integrals $\alpha_{\mathrm{D}}$ and $\alpha_{\mathrm{E}}$, respectively.

If $\alpha_{\mathrm{D} 0}$ is the integral at point $\mathrm{D}$ when water is not ponded, then the value of $\left(\alpha_{D 0}-\alpha_{D}\right)$ is the decrement caused by ponding water, and similarly for point E. This means that the decrement at point $\mathrm{D}$, when the right side paddy field is ponded, is $\left(\alpha_{D 0}-\alpha_{D}\right) /\left(\alpha_{E 0}-\alpha_{E}\right)$ times the decrement at point E. Figure 15.17 shows the results of numerical calculation of uncollided $\gamma$-ray flux; (a) shows integrals of $\alpha_{\mathrm{D}}$ and $\alpha_{\mathrm{E}}$ vs. ponding depth at point $\mathrm{G}$, and (b) shows the ratio $\left(\alpha_{D 0}-\alpha_{D}\right) /\left(\alpha_{E 0}-\alpha_{E}\right)$. As the radiation dose at point $\mathrm{E}$ vs. ponding depth at point $\mathrm{G}$ was formulated by Eq. (15.2), the reduction effect $\Delta y$ by ponding can also be formulated by the following equation. 


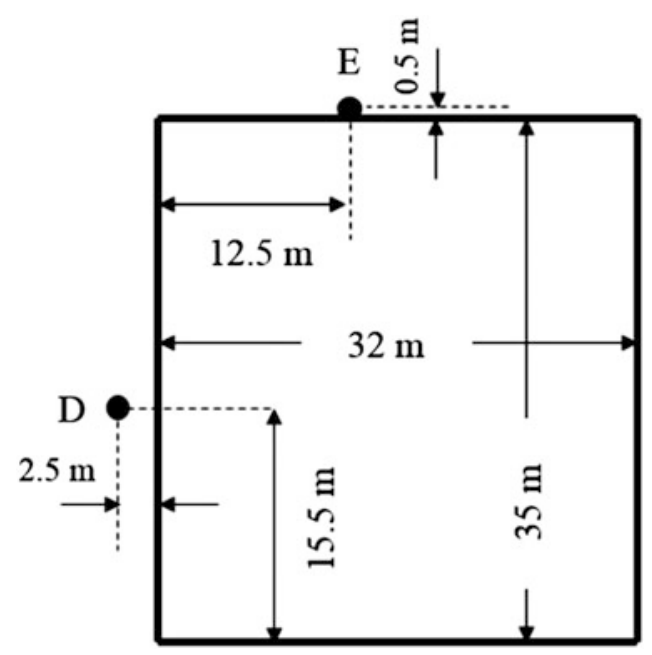

Fig. 15.16 Approximated paddy field for numerical integration. D: Gamma ray observation point on the road. E: Gamma ray observation point in front of the house

(a)

integral $\alpha$ vs. ponding depth

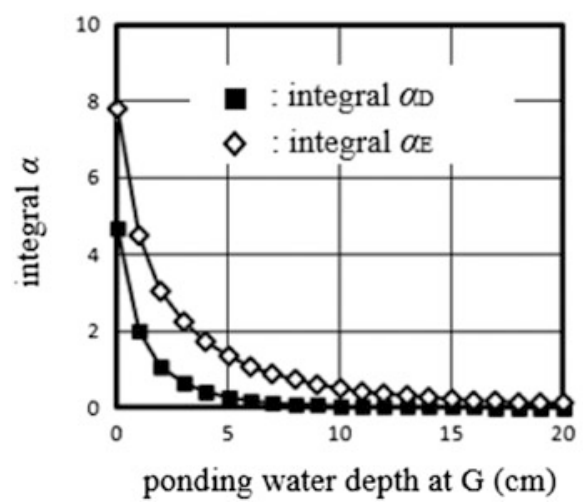

(b) ratio $\left(\alpha_{\mathrm{D} O}-\alpha_{\mathrm{D}}\right) /\left(\alpha_{\mathrm{E} 0}-\alpha_{\mathrm{E}}\right)$

vs. ponding depth

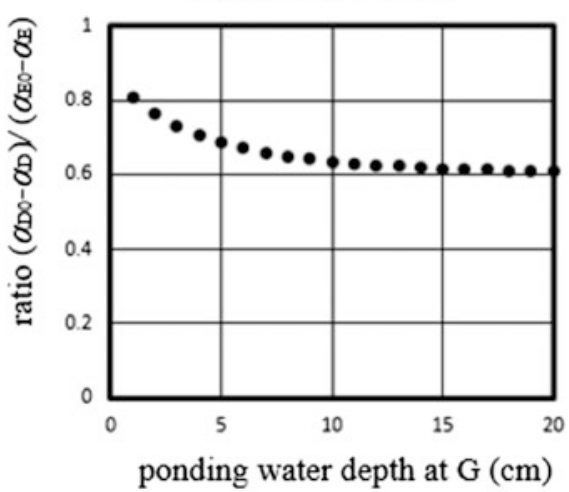

Fig. 15.17 Numerical integral at D and E to compare radiation doses

$$
\Delta y=1.16 \times\{1-\operatorname{Exp}(-8.38 \times(h+0.05))\}
$$

The radiation dose at point $\mathrm{D}$, when the depth at $\mathrm{F}$ is variable but the depth at $\mathrm{G}$ is maintained at $-0.05 \mathrm{~m}$, can be estimated by adding $\Delta y \times\left(\alpha_{D 0}-\alpha_{D}\right) /\left(\alpha_{E 0}-\alpha_{E}\right)$ to the observed radiation dose at $\mathrm{D}$.

Figure 15.18 shows the estimated radiation dose at D vs. ponding depth at $\mathrm{F}$ in the left side paddy field. Compared to the relationship in Fig. 15.15, the radiation dose is more clearly related with ponding depth. The regression curve for plotted points in Fig. 15.18 can be formulated using an exponential function as follows. 
Fig. 15.18 Estimated radiation dose vs. ponding depth at $\mathrm{F}$ if ponding depth at $\mathrm{G}$ was kept at $-0.05 \mathrm{~m}$

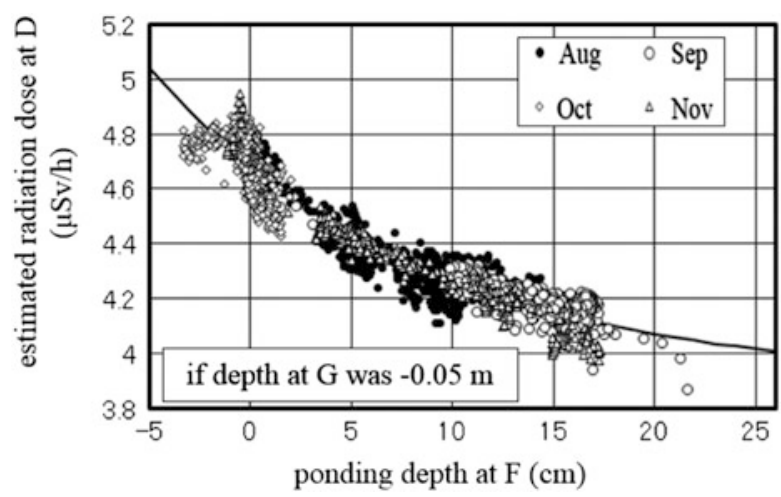

$$
\begin{aligned}
\mathrm{y} & =3.90+1.06 \times \operatorname{Exp}(-7.59 \times(h+0.04)) \\
& =4.96-1.06 \times\{1-\operatorname{Exp}(-7.59 \times(h+0.04))\}
\end{aligned}
$$

This equation implies that the radiation dose at point $\mathrm{D}$ is $4.96(\mu \mathrm{Sv} / \mathrm{h})$ if both paddy fields are not ponded, but it will go down to $3.90(\mu \mathrm{Sv} / \mathrm{h})$ if the ponding depth of the left side paddy field is deep enough. Furthermore, if both paddy fields are deeply ponded, then the radiation dose is reduced to $3.90-1.16 \times 0.6 \cong 3.20(\mu \mathrm{Sv} / \mathrm{h})$. When the two regression equations of Eqs. (15.2) and (15.3) are compared, the background radiation doses are slightly different, $3.54(\mu \mathrm{Sv} / \mathrm{h})$ at $\mathrm{E}$ and $4.96(\mu \mathrm{Sv} / \mathrm{h})$ at $\mathrm{D}$; the potential decrements are similar, $1.16(\mu \mathrm{Sv} / \mathrm{h})$ at $\mathrm{E}$ and $1.06(\mu \mathrm{Sv} / \mathrm{h})$ at $\mathrm{D}$; and the constants of exponent are also similar, -8.38 at $\mathrm{E}$ and -7.59 at D. However, in case of the uncollided $\gamma$-ray flux shown in Fig. 15.17a, the constant of the exponent ranges from -20 to -30 and is fairly different from those in Eqs. (15.2) and (15.3). This difference may be attributed to Compton scattering, but the details are unclear.

\subsection{Conclusions and Remaining Problems}

Through numerical calculations and field experiments we confirmed that paddy fields are potential threats to nearby residents. However, the $\gamma$-ray flux levels, and thus the severity of such threats, can be considerably reduced by deeply ponding these fields. Moreover, before implementing paddy field ponding, certain problems must be solved. First, the differences between numerical and field experimental results should be quantitatively explained; when the ponding was deepened, the uncollided $\gamma$-ray flux decreased exponentially and rapidly, but the radiation dose decreased linearly and gradually. These differences might cause gross errors when the ponding effects are evaluated. Second, water must be deeply and steadily ponded for a long period in the paddy fields. The maximum depth in this field experiment was around $20-25 \mathrm{~cm}$. The following two questions, relating to the 
maximum depth, should be solved: (1) Is this depth deep enough to shield the $\gamma$-rays; and (2) Is it possible to maintain this maximum depth over long periods? According to the numerical calculations, this maximum depth could obstruct nearly all of the uncollided $\gamma$-rays, but it is not clear whether this depth can obstruct all effective $\gamma$-rays, including the scattered rays. Moreover, it is not easy for an ordinary paddy field to maintain water depths between 20 and $25 \mathrm{~cm}$. Paddy field levees are usually not so high and strong, except for those used for deep ponding irrigation and rainwater storage. They is also not protected against cold weather damage. The heights of levees are usually within the range of $20-30 \mathrm{~cm}$, and the ponding depth is usually no more than 50-60\% of the levee's height for stability. Levee improvement for deep ponding should be examined. The ponded water is continuously lost by evapotranspiration and infiltration, and water must be supplied continuously to maintain ponding. The water supply should not contain $\mathrm{Cs}$, therefore the water quality must be monitored and the standard for water intake should be examined. Paddy field ponding has various merits as mentioned before, but at the same time there remain several problems to be solved before it can be implemented.

Acknowledgment The authors are grateful for the financial support of the Grants-in-Aid for Scientific Research (C), Agriculture Restoration; (Grant No. 25517005). The authors also thank Mr. Muneo Kan-no and Mr. Kin-ichi Ohkubo in IIDATE village for their kind cooperation and sincere help with carrying out the field experiments.

Open Access This chapter is distributed under the terms of the Creative Commons Attribution Noncommercial License, which permits any noncommercial use, distribution, and reproduction in any medium, provided the original author(s) and source are credited.

\section{References}

Fujiwara T (2011) Calculation of the space dose rate. http://w3.kcua.ac.jp/ fujiwara/nuclear/air_ dose.html (in Japanese)

Lee S, Senge M, Ito K, Hayashi H (2003) Influence of direct seeding culture in a well-drained and non-tilled paddy field on water requirement-case study on water requirement of Sunami district. Gifu Prefecture Trans JSIDRE 224:19-26 (in Japanese)

Minyu-net (2014) "difficult-to-return zone," "restricted residence area" and "zone in preparation for the lifting of the evacuation order." http://www.minyu-net.com/osusume/daisinsai/saihen. html (in Japanese)

Shiozawa S, Tanoi K, Nemoto K, Yoshida S, Nishida K, Hashimoto K, Nakanishi T, Nihei N, Ono Y (2011) Vertical concentration profiles of radioactive cesium and convective velocity in soil in a paddy field in Fukushima. Radioisotopes 60:323-328 (in Japanese)

Tazaki S (2011) From Becquerel to Sievert. http://www.gakushuin.ac.jp/ 881791/housha/docs/ BqToSv.pdf (in Japanese) 